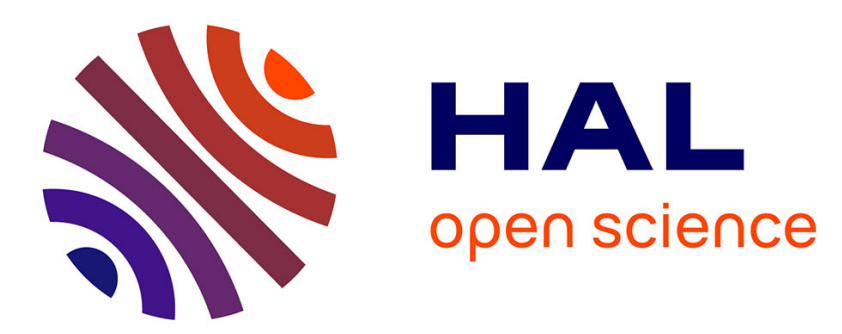

\title{
Robust Constrained Controller Design for HVDC Link Embedded in a Large-scale AC Grid
}

\author{
Elkhatib Kamal, Emile Thau, Bogdan Marinescu, Guillaume Denis
}

\section{To cite this version:}

Elkhatib Kamal, Emile Thau, Bogdan Marinescu, Guillaume Denis. Robust Constrained Controller Design for HVDC Link Embedded in a Large-scale AC Grid. 2020 Electrical Power and Energy Conference, Nov 2020, Edmonton, Alberta (virtual), Canada. 10.1109/EPEC48502.2020.9320009. hal-03172305

\section{HAL Id: hal-03172305 \\ https://hal.science/hal-03172305}

Submitted on 17 Mar 2021

HAL is a multi-disciplinary open access archive for the deposit and dissemination of scientific research documents, whether they are published or not. The documents may come from teaching and research institutions in France or abroad, or from public or private research centers.
L'archive ouverte pluridisciplinaire HAL, est destinée au dépôt et à la diffusion de documents scientifiques de niveau recherche, publiés ou non, émanant des établissements d'enseignement et de recherche français ou étrangers, des laboratoires publics ou privés. 


\title{
Robust Constrained Controller Design for HVDC Link Embedded in a Large-scale AC Grid
}

\author{
Elkhatib Kamal*, Emile Thau*, Bogdan Marinescu* and Guillaume Denis ${ }^{\dagger}$ \\ ${ }^{*}$ Ecole Centrale de Nantes, LS2N-CNRS, 1, rue de la Noë, Nantes 44300, France \\ Email: \{Elkhatib.ibrahim, Emile.Thau, Bogdan.Marinescu\}@ec-nantes.fr \\ ${ }^{\dagger}$ Réseau de Transport d’Eléctricité(RTE) de France, Défense, France, Email: Guillaume.Denis@rte-france.com
}

\begin{abstract}
In this paper, a robust control strategy, able to improve the dynamic behavior performance of High Voltage Direct Current (HVDC) under diverse operating conditions, is proposed. The design of the control proposed in this paper is based on the coordination of the control actions of the HVDC converters and the use of a simplified control model which takes into account not only the HVDC but also its AC neighbor zone. As consequence, stability is ensured for the HVDC and transient stability margin of its AC neighbor zone is improved. From the computational point of view, Linear Matrix Inequalities (LMIs) are solved to compute the gains of regulator which is of standard Proportional-Integral (PI) type. Constrained on both control and the states are also taken into account. This new methodology was validated on a realistic scale model of the France-Spain interconnection in Eurostag. Compared with the standard vector control, Linear Quadratic (LQ) and $H_{\infty}$ approaches, the new proposed controller gives higher critical clearing time (CCT). In addition, the proposed controller improves the dynamic behavior performance under wide range of operating conditions and minimize the tracking reference error with respect to saturations on both control and the states.
\end{abstract}

\section{INTRODUCTION}

Ensuring stability of a power system is a mandatory requirement when considering to increase transfer capability with $\mathrm{AC}$ expansion options enmeshed, to secure the electricity supply to customers. HVDC lines are increasingly often used to reinforce transmission capacity of AC grids [1]. Compared with traditional Line Commutated Converters (LCC), Voltage Source Converter based High Voltage Direct Current (VSCHVDC) has several advantages and adds fast control capability to power transmission. Being active elements, with multiple control degrees of freedom, HVDC line operation is likely to interfere, due to geographic proximity (see e.g. [2]), affecting their stability and that of neighboring AC zones. Recently, rapid advancement has been achieved in the design of robust control strategies for VSC-HVDC systems, such as classic vector control [3], optimal Proportional-Integral (PI) controller using a Linear Quadratic Regulator (LQR) approach [4], optimal, robust, sliding mode control, and artificial intelligencebased methods [5], [6]. In [7] and [8], control synthesis has been shown to improve Critical Clearing Time (CCT) at specific AC critical buses in the HVDC neighborhood. These controllers are generally applied to the appropriately linearized system models built on specific operating situations and the performance degrades when these conditions varies.

The first main contribution of this paper is a proposition and an investigation of a reliable VSC-HVDC control model, which takes into account the dynamics that mostly impact stability of the neighbor AC zone. In [4] a dynamic model based on a class of generators in the HVDC neighbour was used. Here we propose a simplified model which takes into account only the short-circuit powers. The second main contribution is a proposition of a robust controller, that minimizes the tracking reference error and improves the dynamic performances under diverse operating conditions. Saturations on both control and the states are also taken into account. This work concentrates on the fault ride-through capability of the embedded HVDC system which may be exploited to improve its stability. The developed robust control scheme is demonstrated to be effective for temporary short-circuit conditions. The sufficient conditions are formulated in the format of LMIs [9]-[19]. This new methodology was validated on a realistic scale model of the France-Spain interconnection in Eurostag. Compared with the standard vector control, Linear Quadratic (LQ) and $H_{\infty}$ approaches, the new proposed controller gives higher CCT. In addition, the proposed controller minimizes the tracking reference error with respect to the saturations on both control and states.

The paper is organized as follows. In section II, FranceSpain AC grid and its overall VSC-HVDC control model is presented. The control problem formulation is carried out in section III, . The proposed controller structure with respect the saturations on both control and the states is developed in section IV. The effectiveness of the proposed controller is shown by simulation results in section V. Finally, the conclusions and perspectives are given in section VI.

\section{FranCE-SPAIN AC GRID AND ITS OVERALL VSC-HVDC CONTROL MODEL}

The control model which is proposed in [8] is based on the determination of the main dynamics impacting the surrounding power system stability. In our study, we used simpler control model as shown in Figure 1. This led us to design a more efficient robust control design based on LMIs. The proposed VSC-HVDC control model and its identification are presented in the following subsections.

\section{A. Proposed Overall VSC-HVDC Control Model}

The proposed control model is based on monopolar HVDC system with metallic return. It has two conversion stations 


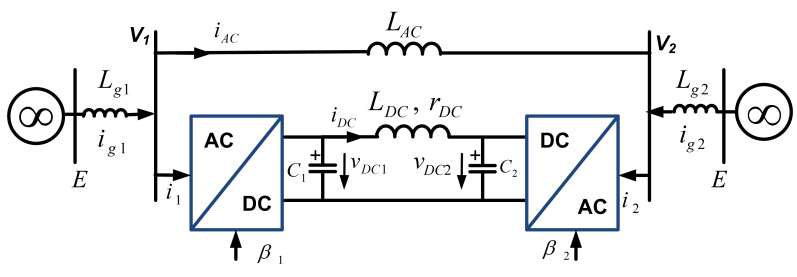

Fig. 1. HVDC power structure control model.

that employ bidirection three-phased (voltage-source) AC-DC power converters, interlinked by a DC cable. The AC grid is represented by infinite buses and equivalent AC lines. HVDC converters are represented by an averaged model [7], [8]. The state is assumed to be observed by an ideal Phase-Locked Loop (PLL). The dynamic equations in $d q$ coordinates of the embedded VSC-HVDC in Figure 1 (derived in [20]) are:

$$
\dot{x}(t)=A x(t)+B u(t) \quad y(t)=C x(t)
$$

with $x(t)=\left[\begin{array}{lllllll}i_{1 d}^{\infty} & i_{1 q}^{\infty} & i_{2 d}^{\infty} & i_{2 q}^{\infty} & V_{D C 1} & V_{D C 2} & i_{D C}\end{array}\right]^{T}$ $=\left[\begin{array}{lllllll}x_{1}(t) & x_{2}(t) & x_{3}(t) & x_{4}(t) & x_{5}(t) & x_{6}(t) & x_{7}(t)\end{array}\right]^{T}$, $y(t)=\left[\begin{array}{llll}V_{D C 1} & Q_{1} & P_{2} & Q_{2}\end{array}\right]^{T}=\left[\begin{array}{llll}y_{1}(t) & y_{2}(t) & y_{3}(t) & y_{4}(t)\end{array}\right]^{T}$, $u(t)=\left[\begin{array}{llll}\beta_{1 d} & \beta_{1 q} & \beta_{2 d} & \beta_{2 q}\end{array}\right]^{T}=\left[\begin{array}{llll}u_{1} & u_{2} & u_{3} & u_{4}\end{array}\right]^{T}$

$$
\begin{aligned}
A & =\left[\begin{array}{ccccccc}
0 & \omega & 0 & 0 & 0 & 0 & 0 \\
-\omega & 0 & 0 & 0 & 0 & 0 & 0 \\
0 & 0 & 0 & \omega & 0 & 0 & 0 \\
0 & 0 & -\omega & 0 & 0 & 0 & 0 \\
0 & 0 & 0 & 0 & 0 & 0 & -\frac{2}{C_{1}} \\
0 & 0 & 0 & 0 & 0 & 0 & \frac{2}{C_{2}} \\
0 & 0 & 0 & 0 & \frac{1}{2 L_{D C}} & -\frac{1}{2 L_{D C}} & -\frac{r_{D C}}{L_{D C}}
\end{array}\right], \\
B & =\left[\begin{array}{cccc}
b_{11} & 0 & b_{13} & 0 \\
0 & b_{22} & 0 & b_{24} \\
b_{31} & 0 & b_{33} & 0 \\
0 & b_{42} & 0 & b_{44} \\
b_{51} & b_{52} & 0 & 0 \\
0 & 0 & b_{63} & b_{64} \\
0 & 0 & 0 & 0
\end{array}\right], C=\left[\begin{array}{cccc}
0 & c_{21} & 0 & 0 \\
0 & c_{22} & 0 & 0 \\
0 & 0 & c_{33} & c_{43} \\
0 & 0 & c_{34} & c_{44} \\
1 & 0 & 0 & 0 \\
0 & 0 & 0 & 0 \\
0 & 0 & 0 & 0
\end{array}\right]^{T},
\end{aligned}
$$

where

$$
\begin{gathered}
b_{11}=-\frac{1}{2}\left(\frac{1}{L_{g 1}}+\frac{1}{L_{A C}}\right) V_{D C 1}=b b_{11} V_{D C 1}, \\
b_{22}=-\frac{1}{2}\left(\frac{1}{L_{g 1}}+\frac{1}{L_{A C}}\right) V_{D C 1}=b b_{22} V_{D C 1}, \\
b_{33}=-\frac{1}{2}\left(\frac{1}{L_{g 2}}+\frac{1}{L_{A C}}\right) V_{D C 2}=b b_{33} V_{D C 2}, \\
b_{44}=-\frac{1}{2}\left(\frac{1}{L_{g 2}}+\frac{1}{L_{A C}}\right) V_{D C 2}=b b_{44} V_{D C 2}, \\
b_{13}=b_{24}=\frac{1}{2} \frac{1}{L_{A C}} V_{D C 2}, \quad b_{31}=b_{42}=\frac{1}{2} \frac{1}{L_{A C}} V_{D C 1}, \\
b_{51}=\frac{3}{2 C_{1}} i_{1 d}^{\infty}, b_{52}=\frac{3}{2 C_{1}} i_{1 q}^{\infty}, b_{63}=\frac{3}{2 C_{2}} i_{2 d}^{\infty}, \\
b_{64}=\frac{3}{2 C_{2}} i_{2 q}^{\infty}, c_{21}=\frac{3}{2} \frac{1}{2} \beta_{1 q}^{\infty} V_{D C 1}, c_{22}=-\frac{3}{2} \frac{1}{2} \beta_{1 d}^{\infty} V_{D C 1}, \\
c_{33}=\frac{3}{2} \frac{1}{2} \beta_{2 d}^{\infty} V_{D C 2}, c_{34}=\frac{3}{2} \frac{1}{2} \beta_{2 q}^{\infty} V_{D C 2}, c_{43}=\frac{3}{2} \frac{1}{2} \beta_{2 q}^{\infty} V_{D C 2}, \\
c_{44}=-\frac{3}{2} \frac{1}{2} \beta_{2 d}^{\infty} V_{D C 2} .
\end{gathered}
$$

where $V_{D C j}$ is the DC voltage, $i_{D C}$ the DC current, $i_{j d}^{\infty}$ and $i_{j q}^{\infty}$ are the grid currents for AC filters, $\beta_{j d}^{\infty}, \beta_{j q}^{\infty}$ are the control inputs of the VSCs, i.e. duty-cycles. $j \in\{1,2\}$ referring to respectively the left and right side of the HVDC. $L_{g 1}, L_{g 2}$, $L_{A C}, r_{D C}, L_{D C}, C_{1}, C_{2}, E$ and $\omega$ are constants.

\section{B. France-Spain Network Application}

The methodology developed in this paper is tested on a realistic model of the France-Spain AC networks shown in Figure 2 [8]. This detailed nonlinear model includes the highvoltage network, 23 generators and their regulations. A VSCbased HVDC link of $65 \mathrm{~km}$ is added to the interconnection between Spain (VIC2) and France (BAIXA1), originally made up of four AC lines. It has a rated pole voltage of $\pm 320 \mathrm{kV}$ and a nominal active power of $1000 M W$ (cf. Figure 3).

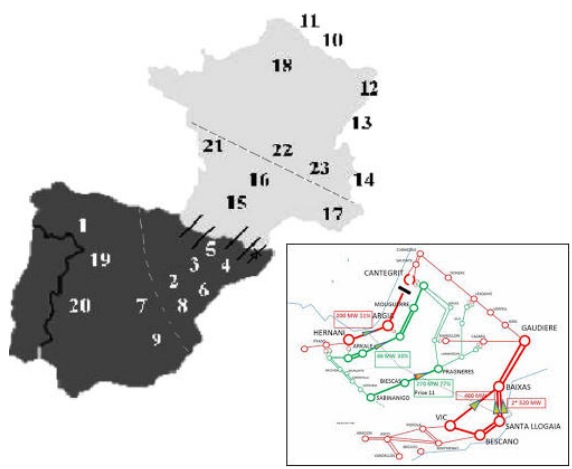

Fig. 2. Location of the 23 machines in the France-Spain network.

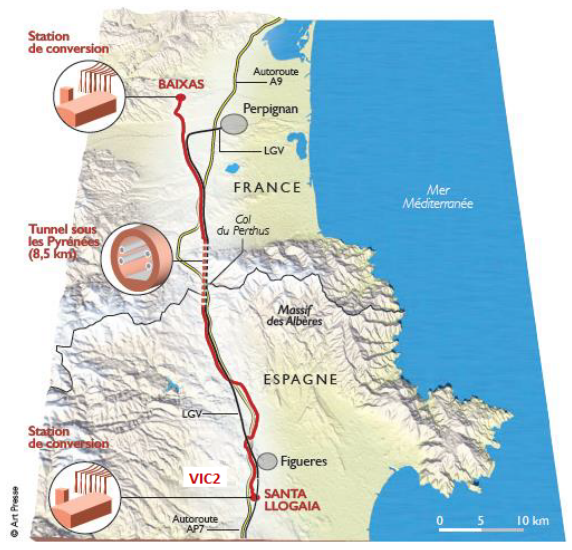

Fig. 3. HVDC link between France-Spain network.

\section{Identification of the Proposed Control Model Parameters}

The parameters of the proposed control model in Figure 1 are identified starting from the full model of the FranceSpain interconnection in Eurostag. To identify the real AC parameters of the network, the system is represented around the BAIXA1 (France) and VIC2 (Spain) nodes as shown in Figure 4, without the DC network, where $X_{g 1}, X_{g 2}$ and $X_{A C}$ are equivalent impedances of the whole system. Voltage of the $\infty$ buses of the control model in Figure 1 is $V=400 k V$, nominal voltage of the system. The control model parameters are identified as the following steps:

1) Two simultaneous short-circuits are applied at BAIXA1 and VIC2 and the short-circuit currents $I_{c c 1}$ and $I_{c c 2}$ are measured (cf. Figure 5). Thus, we can directly estimate 


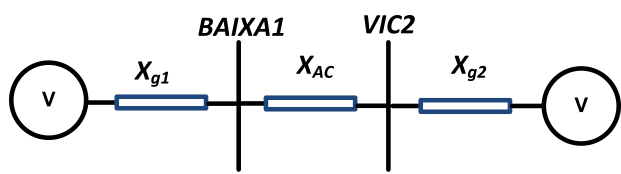

Fig. 4. The node between BAIXA1 (France) and VIC2 (Spain)

$X_{g 1}$ and $X_{g 2}$, since there is no current on the line BAIXA1-VIC2.

$$
X_{g 1}=\frac{\sqrt{3} V}{I_{c c 1}} \quad X_{g 2}=\frac{\sqrt{3} V}{I_{c c 2}}
$$

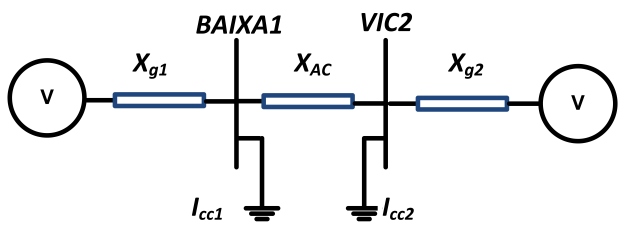

Fig. 5. Short-circuits applied at BAIXA1 and VIC2

2) Short circuit is applied at VIC2 (cf. Figure 6), in order to estimate the reactance $X_{A C}$.

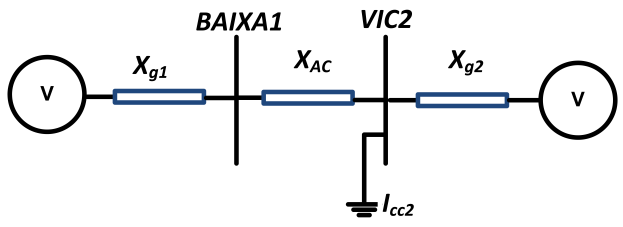

Fig. 6. Short-circuits applied at VIC2

More precisely we can thus estimate the impedance $X_{e q}$, which is the equivalent of the impedance $X_{g 1}$ and $X_{A C}$ in series, all in parallel with $X_{2}$ :

$$
X_{e q}=\frac{\sqrt{3} V}{I_{c c 2}} \quad \rightarrow \quad X_{e q}=\frac{X_{g 2}\left(X_{A C}+X_{g 1}\right)}{X_{1}+X_{g 2}+X_{A C}}
$$

Therefore, the reactance $X_{A C}$ is given by

$$
X_{A C}=\frac{X_{g 2} X_{e q}}{X_{g 2}-X_{e q}}-X_{g 1}
$$

3) Finally, the inductance $L_{A C}$ is computed by $X_{A C}=$ $\omega L_{A C}$ with $\omega=2 \pi$ and $f=100 \pi$.

\section{Control Problem Formulation}

In this paper, the parameter uncertainties, disturbance, states and control inputs constraints are considered as the following:

1) If we consider the system (1) as the following,

$$
\begin{aligned}
\dot{x}(t) & =\left(A+E F_{1}(t) H_{1}\right) x(t) \\
& +\left(B+E F_{2}(t) H_{2}\right) \operatorname{sat}(u(t))+B_{d} w(t) \\
y(t) & =C x(t)+D \operatorname{sat}(u(t))
\end{aligned}
$$

where $E, H_{1}$ and $H_{2}$ are known real constant matrices which represent the parameter uncertainties and $B, F_{1}(t)$ and $F_{2}(t)$ are unknown real matrices with Lebesgue measurable elements, satisfying $F_{i}(t)^{T} F_{i}(t) \leq I \quad, i=1,2, B_{d i} \in \Re^{n \times 1}$ is a known matrix, $w(t)$ is the disturbance vector and function sat represents the nominal saturation as defined after in (10) and $I$ is identity matrix .

2) consider the state constraints is given by;

$$
\gamma=\left\{x \in \Re^{n \times 1} /-q \leq x \leq q ; \quad q \in \Re^{n \times 1}\right\}
$$

(7) can be written as the following

$$
\gamma(M, N)=\left\{x \in \Re^{n \times 1} / M x \leq N\right\}
$$

where $M=[I ;-I]$ and $N=[q ; q]$, therefore $M \in$ $\Re^{h \times n}$ and $N \in \Re^{h \times 1}$ are known. The current and voltage variables are constrained as the following;

$$
\begin{gathered}
-2000 A m p \leq x_{1}, x_{2}, x_{3}, x_{4} \leq 2000 A m p \\
360 K V \leq x_{5}, x_{6} \leq 400 K V
\end{gathered}
$$

3) consider the control input is given by;

$$
\Lambda=\left\{u \in \Re^{m \times 1} /-z \leq u \leq z ; \quad z \in \Re^{m \times 1}\right\}
$$

In this work, $-z=-1 \& z=1$.

4) A state feedback $u(t)=K x(t)$ is designed based on LMIs in order to make the closed-loop system $(A+$ $B K)$ stable. Therefore, an integral action is added to the system in order to follow the setpoints with a steadystate error equal to zero. Four states are added:

$$
\left\{\begin{array}{l}
\dot{x}(t)=A x(t)+B u(t) \\
\dot{x_{8}}=\left(V_{D C 1}-V_{D C 1, r e f}\right. \\
\dot{x_{9}}=\frac{3}{4} V_{D C 2}\left(\beta_{2 d}^{\infty} i_{2 d}^{\infty}+\beta_{2 q}^{\infty} i_{2 q}^{\infty}\right)-P_{2, \text { ref }} \\
\dot{x_{10}}=\frac{3}{4} V_{D C 1}\left(\beta_{1 q}^{\infty} i_{1 d}^{\infty}-\beta_{1 d}^{\infty} i_{1 q}^{\infty}\right)-Q_{1, r e f} \\
\dot{x_{11}}=\frac{3}{4} V_{D C 2}\left(\beta_{2 q}^{\infty} i_{2 d}^{\infty}-\beta_{2 d}^{\infty} i_{2 q}^{\infty}\right)-Q_{2, \text { ref }}
\end{array}\right.
$$

\section{The Proposed Robust Controller And Stability and Robustness ANALYsis}

In this section the robust controller is designed based on LMI in order to make the closed-loop system stable despite the presence of parameter uncertainties, disturbances, states and control constraints. The proposed controller is given by:

$$
u(t)=K X(t)
$$

where $K \in \Re^{m \times n}$ is controller gain. From (6) and (12), the closed loop system dynamics are given by:

$$
\begin{aligned}
\dot{X}(t) & =\left(\bar{A}+E F_{1}(t) H_{1}\right) X(t) \\
& +\left(\bar{B}+E F_{2}(t) H_{2}\right)(K X(t))+\bar{B}_{d} W(t) \\
Y(t) & =\widehat{C} X(t)
\end{aligned}
$$

The main results for the global asymptotic stability of the control system (13) with constrains on the states and the control inputs as well as parameter uncertainties and disturbance are in the following Theorem:

Theorem: The equilibrium of an uncertain control system as given by (13) subject to the constrained states (9) and control inputs (10), with disturbances and parameter uncertainties is asymptotically stable in the whole domain by the controller (12), if the controller gains are set to $K=O G^{-1}$, and there 
exists a positive definite symmetric matrix $P=G^{-1}$ and scalars $\iota, \delta$ and $\beta_{i}$, such that the following LMIs are satisfied,

$$
\begin{gathered}
{\left[\begin{array}{c}
\bar{A} G_{i}+G \bar{A}^{T}+(\bar{B} L)+(\bar{B} L)^{T}+\delta E E^{T}+\frac{1}{\delta} \bar{B}_{d} \bar{B}_{d}^{T} \\
+Z \delta \\
G H_{1}^{T}+L H_{2}^{T} \\
H_{1} Z+H_{2} L
\end{array}\right] \leq 0} \\
{\left[\begin{array}{cc}
1 & L_{l} \\
L_{l}^{T} & G
\end{array}\right] \geq 0 \quad \text { for } \quad 1 \leq l \leq c}
\end{gathered}
$$

where $L_{l}, N_{l}$ and $M_{l}$ are the $l^{\text {th }}$ row of $L, N$ and $M$, respectively and $\iota$ is a constant.

Proof: consider the following quadratic Lyapunov candidate function $V(t)$ is defined as the following:

$$
V(t)=x(t)^{T} P x(t)
$$

where $P$ is a common positive definite matrix. The problem is to find the controller gains $K$ to ensure asymptotic convergence of $X(t)$ toward zero. This problem reduces to finding $P$ and verifying $\dot{V}(t)<0$. Differentiating $V(t)$ with respect to time and substituting (13), gives:

$$
\begin{aligned}
& \dot{V}(t)=\frac{1}{2} X(t)^{T}([(\bar{A}+\bar{B} K) \\
& \left.+\left(E F(t) H_{1}+E F(t) H_{2}\right)\right]^{T} P \\
& +P\left[(\bar{A}+\bar{B} K)+\left(E F(t) H_{1}+E_{2} F(t) H_{2} K\right]\right) X(t) \\
& +\frac{1}{2} W(t)^{T} \bar{B}_{d}^{T} P+P \bar{B}_{d} W(t)
\end{aligned}
$$

From (18), the time derivative of (17) is uniformly negative if

$$
\begin{aligned}
& \left.[\bar{A}+\bar{B} K)+\left(E F(t) H_{1}+E F(t) H_{2}\right)\right]^{T} P \\
& +P\left[(\bar{A}+\bar{B} K)+\left(E F(t) H_{1}+E_{2} F(t) H_{2} K\right]\right. \\
& +\left(\bar{B}_{d}^{T} P+P \bar{B}_{d}\right)<0 \quad \forall i
\end{aligned}
$$

Using Schur complement based on [21], (14) is rewritten as (15) in Theorem Based on Lemma 1 from [19], the LMIs (15), (16) in Theorem are obtained.

\section{SIMULATION TESTS}

In this section the proposed controller is validated. Simulation are carried out on the 23-machines France-Spain benchmark (Section II) with EUROSTAG software (Tractebel Engineering, Belgium and Réseau de Transport d'Electricité (RTE) - France) [8], which provides reliable simulations, particularly for group stability during faults. To check the VSC-HVDC link embedded in AC grid model and the performances of the proposed overall control, three simulations and discussions are presented. The short-circuits are applied at different buses (VIC1, VANDELL and BRAUD location) (cf. Figure 2) near the HVDC link to evaluate the transient stability of the neighbor zone. At each node, several values of the fault elimination time are tested until unstability is reached, i.e, evaluation of the Critical Clearing Time (CCT). The following simulations present the outputs of the system at each node and with different CCT (times are written in the legend of each graph, expressed in milliseconds). The largest CCT value of each curve is the limit of stability.

\section{A. Transient Stability}

The following Figures 7 to 11 present the active and reactive power of the right side (respectively, $P_{2}$ and $Q_{2}$ ), the reactive power and DC voltage of the left side $\left(Q_{1}\right.$ and $V_{D C 1}$, respectively) and gride voltage responses, respectively, of the HVDC converters for different short-circuits deviation (200 ms, $300 \mathrm{~ms}$ and $439 \mathrm{~ms}$ ) occurring at VIC1. Transient oscillations obtained with the proposed strategy are more damped and a good output tracking is also provided.

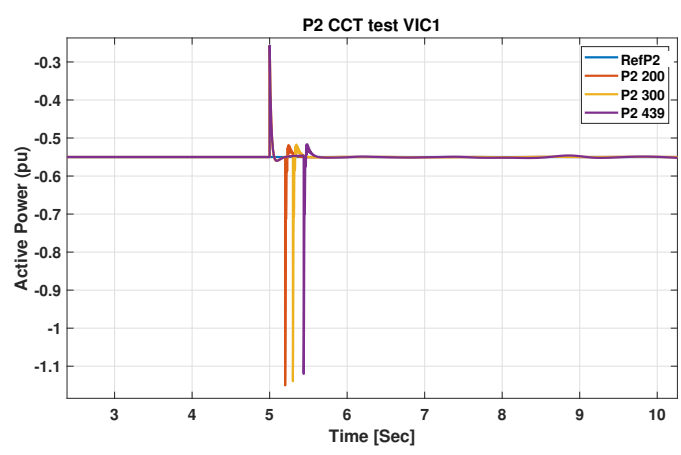

Fig. 7. Time response of active power at $\operatorname{HVDC}\left(P_{2}\right)$.

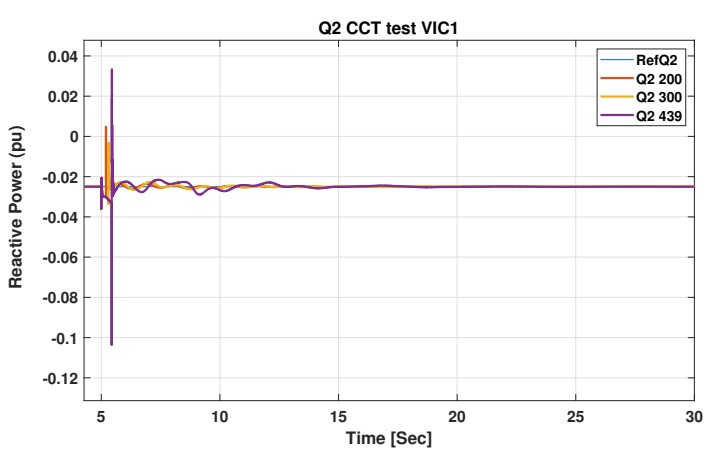

Fig. 8. Time response of reactive power at $\operatorname{HVDC}\left(Q_{2}\right)$.

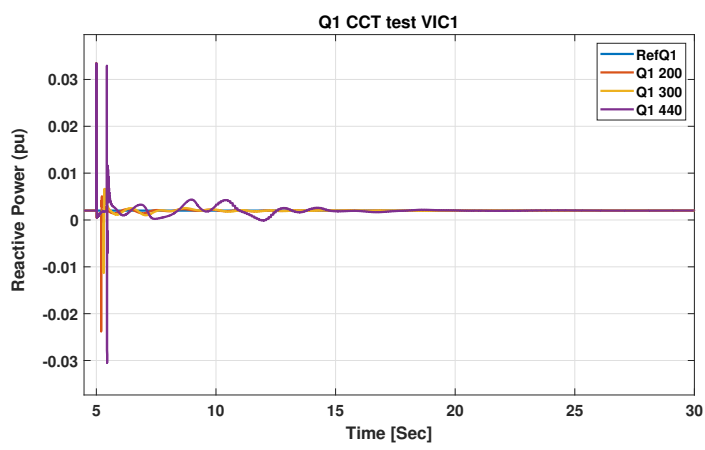

Fig. 9. Time response of reactive power at $\operatorname{HVDC}\left(Q_{1}\right)$. 


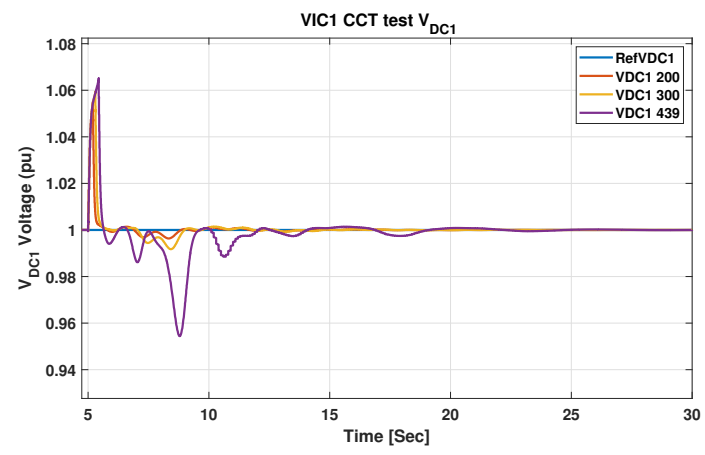

Fig. 10. Time response of the DC voltage $V_{D C 1}$.

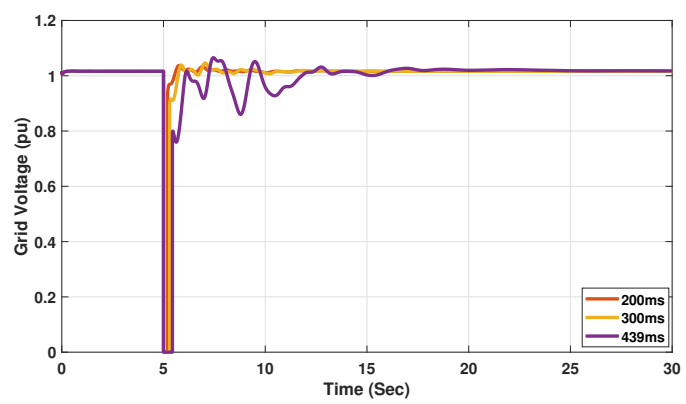

Fig. 11. Time response of the gride voltage at VIC1.

\section{B. Robustness Test at Different Locations of Fault}

In this subsection, the short-circuits are applied at different locations in the grid (VANDELL, and BRAUD), in order to evaluate the impact of the controller not only on the HVDC but also on its neighbor AC zone.

1) Robustness test at VANDELL: Time responses of $P_{2}$ and $Q_{2}, Q_{1}$ and $V_{D C 1}$, are given respectively in Figures 12 to 15 for $100 \mathrm{~ms} / 150 \mathrm{~ms} / 171 \mathrm{~ms}$ short circuits applied at VANDELL.

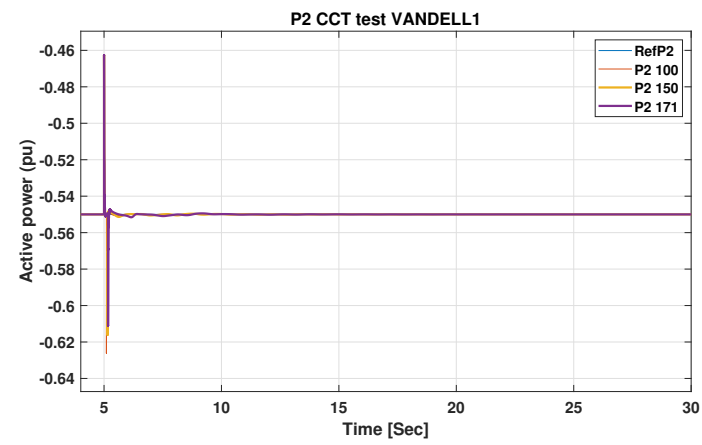

Fig. 12. Time response of active power at $\operatorname{HVDC}\left(P_{2}\right)$.

2) Robustness test at BRAUD: Time response of $V_{D C 1}$ is givenin Figure 16 for $100 \mathrm{~ms} / 150 \mathrm{~ms} / 171 \mathrm{~ms}$ short circuits applied at BRAUD.

For comparative analysis with standard vector control, Linear Quadratic (LQ) and $H_{\infty}$ approaches [8], the CCTs for each are summarized in Table I.

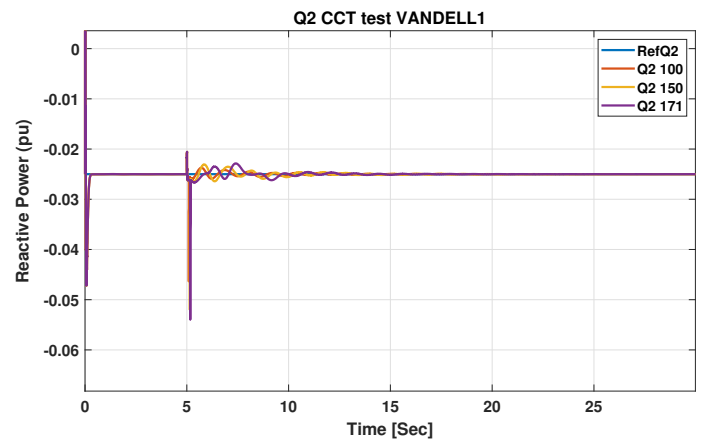

Fig. 13. Time response of reactive power at $\operatorname{HVDC}\left(Q_{2}\right)$.

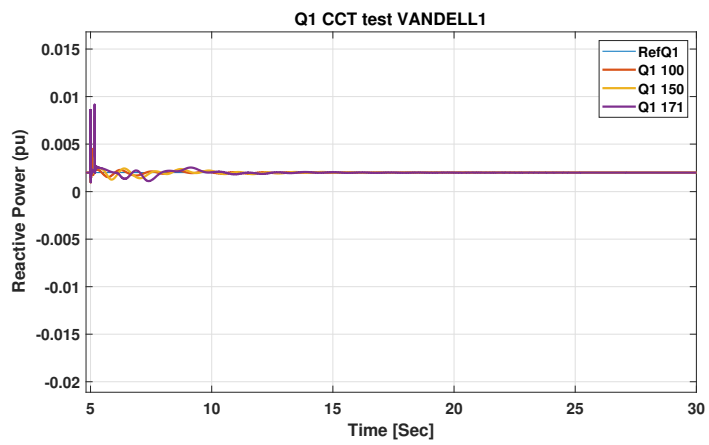

Fig. 14. Time response of reactive power at $\operatorname{HVDC}\left(Q_{1}\right)$.

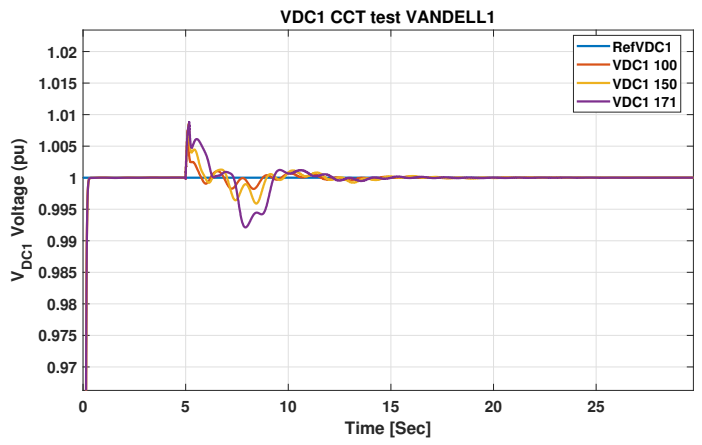

Fig. 15. Time response of the DC voltage $V_{D C 1}$.

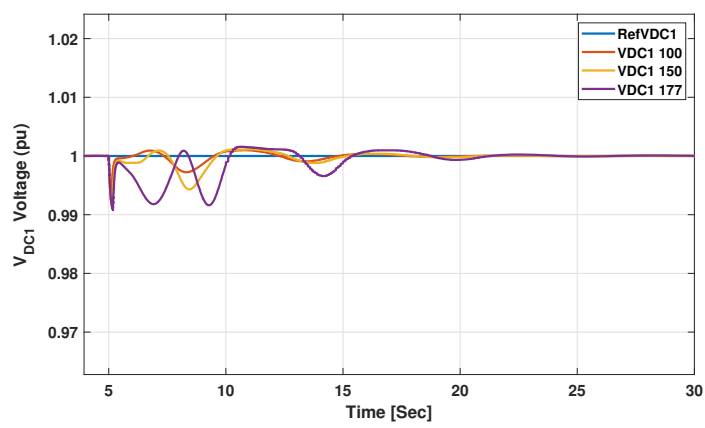

Fig. 16. Time response of the DC voltage $V_{D C 1}$, when short circuits with (100 ms, $150 \mathrm{~ms}$ and $177 \mathrm{~ms}$ ) applied at BRAUD location. 
TABLE I

COMPARISON OF CCT RESUlts FOR PROPOSED CONTROLLER, STANDARD CONTROLlER, LQ CONTROLlER AND $H_{\infty}$ CONTROLLER.

\begin{tabular}{ccccc} 
Location of the fault & Standard controller CCT [ms] & LQ controller CCT [ms] & $H_{\infty}$ controller CCT [ms] & Proposed controller CCT [ms] \\
\hline VIC1 & 223 & 249 & 255 & 439 \\
VANDELL1 & 127 & 130 & 137 & 171 \\
BRAUD & 138 & 140 & 161 & 177 \\
\hline
\end{tabular}

Differences up to $96 \%, 76 \%$ and $72 \%$ are observed between the proposed controller and respectively the standard one, LQ and $H_{\infty}$. Moreover, lower overshoots and time response are registered with the proposed controllers, confirming the improvement of transient stability.

\section{CONCLUSION}

Several studies have shown that controllers of the HVDC links impacts the transient behavior of the surrounding electric system. This can be exploited to improve its stability. The first part of this work develops and validates a simpler control model than the ones previously used in the literature. In the second part of this paper a robust multivariable control design for the converters of an HVDC link is proposed. It is based on the coordination of the control actions of the converters of both HVDC terminals and the use of the control model. In operation, it ensures more tolerance to variation of the grid and converter parameters. Our controller synthesis directly takes into account analytically the actuators security constraints (saturations).

The results of the simulations demonstrated better tracking performances and robustness. This new methodology was validated on a realistic large-scale model of the France-Spain interconnection in Eurostag. Compared with standard vector control, Linear Quadratic (LQ) and $H_{\infty}$ approaches [8], the proposed controller gives higher CCT at the terminals of the HVDC, and in the AC neighbor zone. In addition, the proposed controller improved the dynamic behavior performance under wide range of operating conditions and minimized the tracking reference error with respect the saturations on both control and states. It is planned in the near future to implement the overall proposed control strategy in a hardware-in-the loop platform.

\section{REFERENCES}

[1] N. Flourentzou, V. G. Agelidis and G. D. Demetriades, VSC-based HVDC power transmission systems: An overview. IEEE Trans. on power electron., vol. 24, no. 3, pp. 592-602, 2009.

[2] INELFE Consortium (2017). France-Spain HVDC link. http://www.inelfe.eu/en/projects/baixas-santa-llogaia/. Available May 2017.

[3] W. Leonhard, Control of Electrical Drives: 3rd (Third) edition, SpringerVerlag New York, LLC (September 21, 2001).

[4] L. Arioua, B. Marinescu and E. Monmasson, Control of high voltage direct current links with overall large-scale grid objectives, IET Gener. Transm. Distrib., vol. 8, pp. 945-956, 2014.

[5] M. Durrant, H. Werner and K. Abbott, Synthesis of multi-objective controllers for a VSC HVDC terminal using LMIs. In: Proc. of the 43rd IEEE conf. on decision and control 2004, Bahamas, pp. 4473-4478, December 2004.

[6] A. Colbia-Vega, J. De León-Morales, L. Fridman, O. Salas-Peña and M. Mata-Jiménez, Robust excitation control design using sliding-mode technique for multimachine power systems, Elect. Power Syst Res, vol. 78, pp.1627-1634, 2008
[7] L. Arioua and B. Marinescu, Multivariable control with grid objectives of an HVDC link embedded in a large-scale AC grid, Int. J. Electr. Power Energy Syst., vol.72, pp. 99-108, 2015.

[8] L. Arioua and B. Marinescu, Robust grid-oriented control of high voltage DC links embedded in an AC transmission system, Int. J. Robust Nonlinear Control, vol. 26, pp.1944-1961, 2016.

[9] E. Kamal, A. Aitouche, R. Ghorbani and M. Bayart, Robust nonlinear control of wind energy conversion systems, Int. J. Electr Power Energy Syst., vol.44, no.1, pp. 202-209, 2013.

[10] E. Kamal and A. Aitouche, Robust fault tolerant control of DFIG wind energy systems with unknown inputs, Renewable Energy, vol.56, pp. 215,2013

[11] E. Kamal and A. Aitouche, Fuzzy Observer-Based Fault Tolerant Control Against Sensor Faults for Proton Exchange Membrane Fuel Cells, Int. J. of Hydrogen Energy, vol.45, pp.11220-11232, 2018.

[12] E. Kamal, A. Aitouche, and D. Abbes, Robust fuzzy scheduler fault tolerant control of wind energy systems subject to sensor and actuator faults, Int. J. Electr Power Energy Syst., vol. 55, no.1, pp. 402-419, 2014

[13] E. Kamal, A. Aitouche, Fuzzy fault-tolerant control of wind-diesel hybrid systems subject to sensor Faults, IEEE Transactions on Sustainable Energy, vol. 4, no 4, pp. 857-866, 2013.

[14] E. Kamal, A. Aitouche, Robust scheduler fuzzy controller of DFIG wind energy systems, IEEE Transactions on Sustainable Energy, vol. 4, no 3, pp. 706-715, 2013.

[15] E. Kamal, A. Aitouche, R. Ghorbani and M. Bayart, Robust fuzzy fault tolerant control of wind energy conversion systems subject to sensor faults, IEEE Transactions on Sustainable Energy, vol. 3, no 2, pp. 231241, 2012.

[16] E. Kamal, A. Aitouche and M. Bayart, Intelligent control of WECS subject to parameter uncertainties, Actuator and Sensor Faults, Acta Press, Control and Intelligent Systems, vol. 40, no 3, pp. 1-9, 2012.

[17] E. Kamal, A. Aitouche, R. Ghorbani and M. Bayart, Robust fuzzy logic control of wind energy conversion systems with unknown inputs, Acta Press, International Journal Power and Energy Systems, vol. 32, no 2, pp. 71-81, 2012.

[18] E. Kamal, M. Koutb, A. A. Sobaih and B. Abozalam, An intelligent maximum power extraction algorithm for hybrid wind-diesel-storage system, Int. J. Electr. Power Energy Syst., vol. 32, no. 3, p. 170-177, 2010.

[19] E. Kamal, A. Aitouche, R. Ghorbani and M. Bayart, Fuzzy scheduler fault tolerant control for wind energy conversion systems, IEEE Trans. on Control Syst. Technol., vol. 22, no. 1,pp. 119-131, 2014.

[20] I. Munteanu, B. Marinescu and F. Xavier, Analysis of the interactions between close HVDC links inserted in an AC grid, Proc. of the 2017 IEEE Power \& Energy Soc. General Meeting, Chicago, Illinois, USA, July 2017, pp. 1-5.

[21] F. Zhang, The Schur Complement and Its Applications, SBN: 978-0387-24271-2, 2005. 